\title{
A group of ectomycorrhizal fungi restricts organic matter accumulation in boreal forest 10
}

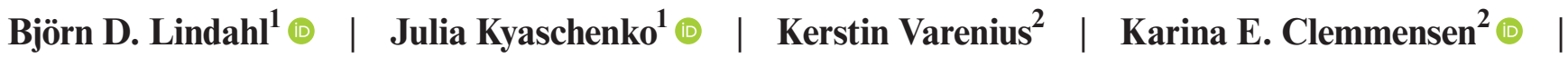

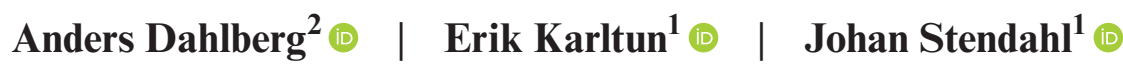

${ }^{1}$ Department of Soil and Environment, Swedish University of Agricultural Sciences, Uppsala, Sweden

${ }^{2}$ Department of Forest Mycology and Plant Pathology, Swedish University of Agricultural Sciences, Uppsala, Sweden

Correspondence

Björn D. Lindahl, Department of Soil and Environment, Swedish University of Agricultural Sciences, Box 7014, SE-750 07 Uppsala, Sweden.

Email: Bjorn.Lindahl@slu.se

Funding information

Swedish Research Council FORMAS, Grant/Award Number: 2011-1747 and 20121257; Swedish Environmental Protection Agency

Editor: Dr. Tadashi Fukami

\begin{abstract}
Boreal forest soils are important global carbon sinks, with significant storage in the organic topsoil. Decomposition of these stocks requires oxidative enzymes, uniquely produced by fungi. Across Swedish boreal forests, we found that local carbon storage in the organic topsoil was 33\% lower in the presence of a group of closely related species of ectomycorrhizal fungi - Cortinarius acutus s.1.. This observation challenges the prevailing view that ectomycorrhizal fungi generally act to increase carbon storage in soils but supports the idea that certain ectomycorrhizal fungi can complement free-living decomposers, maintaining organic matter turnover, nutrient cycling and tree productivity under nutrient-poor conditions. The indication that a narrow group of fungi may exert a major influence on carbon cycling questions the prevailing dogma of functional redundancy among microbial decomposers. Cortinarius acutus s.l. responds negatively to stand-replacing disturbance, and associated population declines are likely to increase soil carbon sequestration while impeding long-term nutrient cycling.
\end{abstract}

\section{K E Y W O R D S}

carbon sequestration, decomposition, functional guilds, functional redundancy, fungal communities, metabarcoding, mor layer, nitrogen, soil, statistical modelling

\section{INTRODUCTION}

It is well-recognised that impacts of biological species and their traits propagate through ecosystems, affecting processes and, ultimately, ecosystem services (Mace et al., 2012). Yet, the influence of individual microbial taxa at the ecosystem scale is often questioned, and the potential of microbial community composition to affect ecosystem functioning is one of the major unresolved questions in terrestrial ecology (Schimel 1995; Schimel \& Schaeffer, 2012; Graham et al., 2016). The pivotal role of microorganisms as drivers of ecosystem processes is indisputable, but functional redundancy among microorganisms has been thought to restrict influence of microbial diversity and community composition on overall process rates (Andrén \& Balandreau, 1999; Nannipieri et al., 2003). Holistic approaches based on measurements of pools and fluxes have prevailed (Nannipieri et al., 2003), and microbial communities have largely been treated as a "black box" (Schloter et al., 2018). However, recent evidence suggests that microbial keystone taxa may exert a major influence on community functions (Banerjee et al., 2018). Our capacity to understand variation in ecosystems and predict responses to disturbance and global change is severely impeded by poor knowledge of the interplay between microbial community composition, traits and functions (Allison

This is an open access article under the terms of the Creative Commons Attribution License, which permits use, distribution and reproduction in any medium, 
\& Martiny, 2008; Clemmensen et al., 2015; Glassman et al., 2018; McGuire \& Treseder, 2010; Philippot et al., 2013; Strickland et al., 2009).

In mineral soils, storage and stability of organic matter is largely regulated by physical protection in aggregates rather than by inherent biochemical recalcitrance (Schmidt et al., 2011). Boreal forest soils are an important exception, with the purely organic topsoils constituting a relatively unprotected carbon pool that is of global significance (DeLuca \& Boisvenue, 2012). Decomposition of soil organic matter is usually considered a "broad" process, carried out by a diverse assembly of microorganisms with a high degree of functional redundancy (Schimel 1995; Nannipieri et al., 2003). However, Schimel and Schaeffer (2012) hypothesised that "In physically unprotected organic detritus, chemical structures remain complex and specific to the plant, microbe, or animal that produced them; exoenzyme breakdown is necessary for microbes to metabolise them. Thus, their breakdown remains under biological control and sensitive to the specific identities of the decomposers present". As decomposition of more recalcitrant organic pools depends on a subset of more capable microbial decomposers, it may be a more "narrow" process in terms of redundancy (McGuire \& Treseder, 2010). Organic matter in boreal forest topsoil (the mor layer) has its origin primarily in root litter and fungal mycelium (Adamczyk et al., 2019; Clemmensen et al., 2013; Kyaschenko et al., 2019), and there is evidence that pool sizes are regulated largely by the rate of degradation of biochemically demanding compounds, primarily by manganese-dependent peroxidase enzymes (Keiluweit et al., 2015; Kyaschenko et al., 2017a; Stendahl et al., 2017). Manganese peroxidases have evolved uniquely within the fungal class Agaricomycetes (Floudas et al., 2012), which among others contains most "mushroom forming" fungi. This phylogenetic limitation of potent decomposer capacity to a specific group of microorganisms may reduce functional redundancy.

Microbial communities in boreal forest soils are characterised by a large contribution of ectomycorrhizal fungi, which live in symbiosis with tree roots (Högberg \& Högberg, 2002; Read \& Perez-Moreno, 2003). Interactions between symbiotic ectomycorrhizal fungi and free-living saprotrophs play a central role in the regulation of carbon accumulation in forest ecosystems (Averill et al., 2014; Kyaschenko et al., 2017a; Talbot et al., 2013). As ectomycorrhizal fungi may both hamper and promote accumulation of organic matter below ground (Frey 2019), there is a need to assess the importance and direction of ectomycorrhizal links to organic stocks across large spatial scales. Most ectomycorrhizal fungi have lost the capacity to decompose during evolution from saprotrophic ancestors (Kohler et al., 2015). Ectomycorrhizal fungi have therefore been proposed to hamper decomposition by competing with saprotrophic decomposers and thereby promote accumulation of organic matter (Averill \& Hawkes, 2016; Averill et al., 2014;
Gadgil \& Gadgil, 1975; Kyaschenko et al., 2017a; Orwin et al., 2011). However, this "Gadgil effect" is context dependent (Fernandez \& Kennedy, 2016; Fernandez et al., 2020; Smith \& Wan, 2019), and even when in operation, its quantitative importance for belowground carbon storage has been questioned (Sterkenburg et al., 2018).

In contrast to most lineages of ectomycorrhizal fungi, the genetic capacity to produce manganese peroxidase has been retained in a limited number of taxa, notably members of the "webcap" genus Cortinarius (Bödeker et al., 2014). Experimental exclusion of ectomycorrhizal fungi (Sterkenburg et al., 2018) and decline in ectomycorrhizal fungi associated with high tree mortality after wildfire (Pérez-Izquierdo et al., 2021) reduced manganese peroxidase activity radically in Swedish boreal forests. Furthermore, spatial correlation between manganese peroxidase activity and Cortinarius DNA markers was observed in a pine chronosequence (Kyaschenko et al., 2017b), and high abundance of Cortinarius species coincided with more rapid organic matter turnover in forest on islands in a northern Swedish lake (Clemmensen et al., 2015). Across a local transect from alpine heath to subarctic birch forest, increasing prevalence of Cortinarius species was linked to lower below-ground carbon storage in the forest, in spite of higher litter input (Clemmensen et al., 2021).

These reports led us to hypothesise that presence of ectomycorrhizal Cortinarius species would correlate with low stocks of organic matter in the topsoil of boreal forests. This hypothesis challenges two widespread null hypotheses:

1. That microbial community composition has little influence on decomposition (Andrén \& Balandreau, 1999; Nannipieri et al., 2003), or that such influence is related to abundance of broad functional guilds, rather than phylogenetically more narrow taxa (Schimel \& Schaeffer, 2012);

2. That ectomycorrhizal fungi generally increase organic matter storage by suppressing saprotrophic decomposers (Averill \& Hawkes, 2016; Averill et al., 2014; Gadgil \& Gadgil, 1975; Kyaschenko et al., 2017a; Orwin et al., 2011).

To test our hypothesis, we used high-throughput sequencing of DNA markers (Nilsson et al., 2019) to analyse Agaricomycetes communities in the organic topsoil of boreal forest stands, systematically distributed across a wide geographical area, in conjunction with the National Forest Inventory of Sweden. Due to the large size and longevity of Agaricomycetes individuals in boreal forest soils (Dahlberg \& Stenlid, 1994) we expected that the presence of Cortinarius species would be reflected in low organic matter stocks, conditional on other important drivers. Although the study relied on correlative relations, it is important to point out that the data were used to test a clear a priori hypothesis, based 
on previous studies, rather than to draw inductive posthoc conclusions (Prosser, 2020).

\section{MATERIALS AND METHODS}

\section{Sampling}

Sampling was carried out in June-September 2014-2016 in connection with the Swedish Forest Soil Inventory (Fridman et al., 2014). The soil inventory collects data from locations that are distributed systematically in a grid across Sweden. We sampled the organic topsoil in $3 \mathrm{~m}^{2}$ plots, geographically distributed across Swedish boreal forest land. Our sampling campaign covered a $240000 \mathrm{~km}^{2}$ area, spanning the entire latitudinal range of the boreal forest biome (Fig. S1). Two data sets were analysed: "all forests" encompassed 359 stands distributed in the boreal part of Sweden. Only forest stands with more than $70 \%$ of the tree basal area consisting of conifers and an organic topsoil (mor layer; O horizon) that was distinct from the mineral soil beneath were included. Stands with Sphagnum peat were excluded. "Old forests" was distinguished as a subset of "All forests" that included 173 stands older than 60 years, to avoid disturbance by clear-cutting forestry. The study area extended from $60^{\circ}$ to $68^{\circ} \mathrm{N}$ and from $12^{\circ}$ to $24^{\circ} \mathrm{E}$ with the stands more or less evenly distributed across the area, albeit with a somewhat higher density in the southern parts.

At each stand, basal area, species composition and average age (weighted by basal area) of trees were assessed within a $10 \mathrm{~m}$ radius circle. For estimation of organic stocks, samples of the organic topsoil were collected with a $10 \mathrm{~cm}$ diameter corer at 1-9 locations along a $60 \mathrm{~cm}$ radius circle within the larger circular area. After removal of freshly fallen, structurally intact plant litter, cores were collected, spanning the entire organic topsoil down to the mineral soil transition (or to rock in sites without mineral soil), until at least 1.51 of organic matter was collected. The mass of the topsoil was calculated on an area basis by drying, sieving ( $2 \mathrm{~mm}$ mesh) and weighing the samples, and dividing the dry weight by the total area of the collected cores. Carbon and nitrogen concentrations were determined using an elemental analyser (TruMac $\mathrm{CN}$; LECO), and topsoil carbon stocks were determined by multiplying carbon concentrations with the topsoil mass. The nitrogen concentration of organic matter was expressed relative to the carbon content (i.e. as the $\mathrm{N}: \mathrm{C}$ ratio). The $\mathrm{pH}$ in the topsoil was determined in a slurry consisting of $2 \mathrm{~g}$ soil and $25 \mathrm{ml}$ deionised water, using an 855 Robotic Titrosampler with an Aquatrode Plus combined $\mathrm{pH}$ electrode (Metrohm, Herisau, Switzerland).

Separate samples of the organic topsoil were collected for analysis of the fungal community. For this purpose, material from the uppermost $10 \mathrm{~cm}$ was collected and pooled from five locations within a $1 \mathrm{~m}$ radius circle $\left(3 \mathrm{~m}^{2}\right)$ concentric with the $60 \mathrm{~cm}$ radius circle. Samples were, on average, frozen within 8 days after sampling, freeze-dried and finely ground in a ball mill.

\section{Sequencing of fungal ITS markers}

DNA was extracted from $50 \mathrm{mg}$ of organic soil, using the NucleoSpin Soil kit (Macherey-Nagel), and the ITS2 region was amplified using the fungal-specific primers gITS7 and a 3:1 mix of the reverse primers ITS4 and ITS4arch, with both forward and reverse primers fitted with unique 8 bp sample identification tags (Ihrmark et al., 2012; Clemmensen et al. 2016). DNA extracts were diluted to $0.25 \mathrm{ng} / \mu 1$ in a $50-\mu 1$ PCR reaction volume and amplified using the following cycling programme: $5 \mathrm{~min}$ at $95^{\circ} \mathrm{C} ; 20-35$ cycles of $30 \mathrm{~s}$ at $95^{\circ} \mathrm{C}, 30 \mathrm{~s}$ at $56^{\circ} \mathrm{C}$ and $30 \mathrm{~s}$ at $72^{\circ} \mathrm{C} ; 7 \mathrm{~min}$ at $72^{\circ} \mathrm{C}$. The number of PCR cycles was optimised for each sample by re-running samples with too strong or too weak PCR products (according to gel electrophoresis) with cycle numbers adopted to obtain "weak but visible" bands on the gel (Castaño et al., 2020). PCR products were run in duplicates, which were pooled and cleaned using the AMPure kit (Beckman Coulter Inc.). DNA concentrations were established using a Qubit fluorometer (Life Technologies), and DNA from each sample was pooled and purified again using the E.Z.N.A. Omega cycle pure kit (Omega Biotek). Amplicon size distribution was pre-checked using the 2100 Bioanalyzer system (Agilent) and composite samples were sequenced on the RSII platform (Pacific Biosciences) by SciLifeLab NGI (Uppsala, Sweden) after addition of sequencing adaptors by ligation. The PacBio platform was chosen to minimise bias caused by size variation in the amplicon pool, which is considerable for the fungal ITS2 region (Castaño et al., 2020).

\section{Bioinformatics}

Sequences were filtered and clustered using the SCATA pipeline (scata.mykopat.slu.se; Ihrmark et al., 2012). Sequences were quality checked to remove sequences shorter than $100 \mathrm{bp}$, with mean quality scores lower than 20 , with individual bases with a quality score lower than 3 , or with a missing 3' or 5' tag. Sequences were screened for the gITS7 and ITS4 primers, requiring a minimum match of $90 \%$, and reverse complemented if necessary. Globally unique genotypes were removed to reduce the incidence of sequencing errors. Quality filtering removed $53 \%$ of the total sequences, and another $16 \%$ were removed as unique genotypes. Remaining sequences were clustered into species hypotheses (hereafter species; Kõljalg et al., 2013) through pairwise comparisons with USEARCH (Edgar, 2010) followed by single linkage clustering, with the minimum similarity to the closest neighbour required to enter a cluster set at $99 \%$. 
The most abundant sequence from each species was selected as a representative and was identified by BLAST comparisons with the UNITE (Kõljalg et al., 2013) and NCBI databases. After removal of non-fungal sequences $(15 \%)$, all species that accounted for more than $1 \%$ of the sequences in any sample were evaluated manually for taxonomic identity and ectomycorrhizal status. The relative abundance of ectomycorrhizal fungi was calculated for each sample as the summed number of sequences assigned to ectomycorrhizal species divided by the total number of sequences from all identified species. The relative abundance of saprotrophic Agaricomycetes was calculated in a similar way, based on all Agaricomycetes species that were not assigned as ectomycorrhizal or belonged to the order Sebacinales (thus, the saprotroph group may have contained some parasitic taxa). The genus Cortinarius was recorded as present whenever any species in the genus accounted for more than $1 \%$ of the fungal sequences in a sample.

Clustering was repeated with $94-98 \%$ clustering thresholds, grouping sequences into broader phylogenetic clusters. Representative sequences from the $99 \%$ clustering were included during clustering, to enable tracing of species among the broader sequence clusters. For each sequence clustering level a "core Agaricomycetes community" was derived, containing all Agaricomycetes sequence clusters that were present at more than $10 \%$ of the "Old forests" stands ( $>17$ stands), with a relative abundance higher than $1 \%$ of the total amplicon pool required for a sequence cluster to be recorded as present.

\section{Statistics}

The annual temperature sum, calculated as a function of latitude and altitude (Odin et al., 1983), was used as a climate index. Tree basal area was used to represent tree biomass. Tree species distribution was expressed as $\%$ Picea abies of the total basal area of conifers (Picea abies and Pinus sylvestris). To reduce the impact of deviating data points on statistical models, the topsoil carbon pool, $\mathrm{pH}$ and relative abundance of saprotrophic Agaricomycetes were log-transformed, whereas the nitrogen concentration of organic matter $(\mathrm{N}: \mathrm{C})$ and relative abundance of ectomycorrhizal fungi were square root-transformed. After these transformations, all data were evenly distributed around the means.

The smaller set of 173 old forest stands was used to evaluate potential direct and indirect predictors of carbon stocks in the organic topsoil. The genus Cortinarius as a whole was tested as a binary predictor (presence/ absence) in a linear model with soil nitrogen, soil $\mathrm{pH}$, temperature, tree biomass, tree species, ectomycorrhizal fungi and saprotrophic Agaricomycetes as covariates. The overall correlation between the composition of the core Agaricomycetes community, at different clustering thresholds, and the topsoil carbon pool was estimated by fitting logistic regression models to the occurrence (presence/absence) of Agaricomycetes sequence clusters with the carbon pool as explaining variable. Communityaggregated statistics were derived using mvabund (Wang et al., 2012), and the strongest correlation with the carbon pool was found with the community clustered at $96 \%$ single linkage similarity (Fig. S2). Individual sequence clusters ( $96 \%$ sequence similarity) of the core Agaricomycetes community were then evaluated as predictors of the carbon pool by including them one by one as binary variables (presence/absence with a relative abundance $>1 \%$ required to be recorded as present) in the carbon stock model. We chose to represent fungal taxa by their presence/absence rather than their momentary relative abundance at the time of sampling, considering the dynamic nature of fungal communities in relation to the slow change of organic matter stocks. A sequence cluster containing the ectomycorrhizal species Cortinarius acutus and closely related taxa (C. acutus s.1.) was singled out as a significant ( $p=0.0015$ ) predictor of the carbon pool (Table 1), both with and without Bonferroni correction for multiple tests $(\alpha=0.0045)$. Raw Pearson correlations between parameters are presented in Fig. S3.

A piecewise structural equation model was fitted using the R-package piecewiseSEM (Lefcheck, 2016) according to the relationships presented below. Presence of C. acutus s.l. was modelled with a binomial

TA B LE 1 Significances of correlations between carbon stocks and presence of Cortinarius or core Agaricomycetes

\begin{tabular}{lllll}
\hline Taxa & Obs. & $\begin{array}{l}\text { Freq. } \\
\mathbf{( \% )}\end{array}$ & $\boldsymbol{t}$-value & $\boldsymbol{p}$ \\
\hline The genus Cortinarius & 82 & 47 & -2.08 & $\mathbf{0 . 0 3 9}$ \\
$\begin{array}{l}\text { Piloderma } \\
\quad \text { sphaerosporum }\end{array}$ & 80 & 46 & 0.61 & 0.54 \\
$\begin{array}{l}\text { Tylospora fibrillosa } \\
\text { Piloderma olivaceum/ }\end{array}$ & 50 & 29 & 1.22 & 0.22 \\
$\quad$ bicolor & 50 & 29 & -0.72 & 0.47 \\
Cortinarius spp. & 44 & 25 & -1.59 & 0.11 \\
Mycena spp. & 37 & 21 & -0.23 & 0.82 \\
Suillus variegatus & 32 & 18 & -0.63 & 0.10 \\
Russula decolorans & 25 & 14 & -0.77 & 0.44 \\
Cortinarius acutus $\mathrm{s} .1$. & 23 & 13 & -3.23 & $\mathbf{0 . 0 0 1 5}$ \\
Lactarius rufus & 22 & 13 & -1.18 & 0.24 \\
Cortinarius mucosus & 22 & 13 & -1.53 & 0.13 \\
Piloderma byssinum & 19 & 11 & 1.32 & 0.19 \\
\hline
\end{tabular}

Significances of the genus Cortinarius and core Agaricomycetes (clusters at $96 \%$ sequence similarity present in $>10 \%$ of the stands) as predictors of carbon stocks in the organic top-soil of old boreal forest stands in Sweden $(N=173)$. Occurrences of taxa, based on ITS2 markers, were included as binomial predictors (presence/absence) of log transformed C stocks with temperature, soil $\mathrm{N}$ concentration, soil $\mathrm{pH}$, tree species, tree biomass and relative abundances of saprotrophic Agaricomycetes and ectomycorrhizal fungi as covariates in a linear model with 164 degrees of freedom. Individual tests were conducted for each fungal taxa and $p$-values $<0.05$ are indicated in bold. Obs. denotes the number of stands in which a taxon occurred and Freq. denotes the frequency of observation $(100 *$ Obs./173). 
linking function (i.e. logistic regression) after backward selection of predictors based on AIC in the Rpackage MASS.

$$
\begin{aligned}
\sqrt{\text { conc. }}= & \alpha_{1}+\beta_{1} \text { Temperature }+\beta_{2} \ln (p H)+\beta_{3} \text { Spruce } \\
& +\beta_{4} \text { Tree biomass }+\varepsilon_{1} \\
\sqrt{E C M}= & \alpha_{2}+\beta_{5} \sqrt{\text { Nconc. }}+\beta_{6} \text { Temperature }+\beta_{7} \ln (p H) \\
+ & \beta_{8} \text { Spruce }+\beta_{9} \text { Tree biomass }+\varepsilon_{2}
\end{aligned}
$$

$$
\begin{aligned}
\ln (S A P)= & \alpha_{3}+\beta_{10} \sqrt{\text { Nconc. }}+\beta_{11} \text { Temperature }+\beta_{12} \ln (p H) \\
& +\beta_{13} \text { Spruce }+\beta_{14} \text { Tree biomass }+\varepsilon_{3}
\end{aligned}
$$

$$
\begin{aligned}
& \text { Prob. }(\text { C. acutus })=\alpha_{4}+\beta_{15} \sqrt{N \text { conc. }}+\beta_{16} \text { Tree biomass } \\
& +\beta_{17} \sqrt{E C M}+\varepsilon_{4} \\
& \begin{aligned}
\ln (\text { C pool })= & \alpha_{5}+\beta_{18} \sqrt{\text { Nconc. }}+\beta_{19} \text { Temperature }+\beta_{20} \ln (p H) \\
& +\beta_{21} \text { Spruce }+\beta_{22} \text { Tree biomass }+\beta_{23} \ln (S A P) \\
& +\beta_{24} \sqrt{E C M}+\beta_{25} \text { C. acutus }+\varepsilon_{5}
\end{aligned}
\end{aligned}
$$

where $\alpha_{1-5}$ denote model intercepts, $\beta_{1-25}$ denote correlation coefficients and $\varepsilon_{1-5}$ denote error terms. "Soil N" denotes the nitrogen concentration of organic matter $(\mathrm{N}: \mathrm{C})$, "Temperature" denotes the annual temperature sum (Odin et al., 1983), "Spruce" denotes the share of the coniferous basal area that was Picea abies and "Tree biomass" denotes basal area of conifers. "SAP" and "ECM" denote the relative sequence abundances of saprotrophic Agaricomycetes and ectomycorrhizal fungi, respectively, among all fungal DNA markers. "C. acutus" refers to presence of the ectomycorrhizal fungus $C$. acutus s.1., with relative sequence abundance $>1 \%$ required to be recorded as present. " $\mathrm{C}$ pool" refers to the amounts of carbon in the organic topsoil expressed on an area basis.

The larger data set, which included both younger stands that were planted after clear-cutting, as well as stands with long continuity, was used to evaluate dynamics of $C$. acutus s.l. after stand-replacing forest harvest, using piecewise structural equation modelling (Lefcheck, 2016) according to relationships presented below. Presence of $C$. acutus s.l. was modelled with a binomial linking function. Stand age (time since harvest and subsequent planting) was initially included both non-transformed and square root-transformed, to test for second order relationships, and the least correlated variable was removed unless both were significant.

$$
\begin{gathered}
\sqrt{N \text { conc. }}=\alpha_{6}+\beta_{26} \sqrt{\text { Standage }}+\varepsilon_{6} \\
\sqrt{E C M}=\alpha_{7}+\beta_{27} \sqrt{N \text { conc. } .}+\beta_{28} \sqrt{\text { Standage }}+\beta_{29} \text { Standage }+\varepsilon_{7} \\
\text { Prob. }(\text { C.acutus })= \\
\alpha_{8}+\beta_{30} \sqrt{N \text { conc. }} \\
+\beta_{31} \sqrt{E C M}+\beta_{32} \sqrt{\text { Standage }}+\varepsilon_{8}
\end{gathered}
$$

where $\alpha_{6-8}$ denote model intercepts, $\beta_{26-32}$ denote correlation coefficients and $\varepsilon_{6-8}$ denote error terms. "Stand age" refers to the average age of trees weighted by basal area.

\section{RESULTS}

Sequencing yielded on average 1247 (range: 217-7917) high quality PacBio reads per sample. Agaricomycetes accounted for $27 \%$ of the fungal sequences among the 173 stands that were older than 60 years. The remaining fungal community consisted of Ascomycota and Zygomycota, which lack manganese peroxidases and are generally weak decomposers compared to most Agaricomycetes decomposers. The ectomycorrhizal community was dominated by the genera Cortinarius, Piloderma and Russula, and Mycena was the most common genus among saprotrophic Agaricomycetes (Fig. S4). The core community of Agaricomycetes that accounted for $>1 \%$ of the sequences on more than $10 \%$ of the stands (at a 96\% similarity single-linkage clustering threshold) encompassed 11 phylogenetic groups.

Presence of the genus Cortinarius as a whole correlated negatively with carbon stocks, conditional on climate, soil $\mathrm{pH}$ and nitrogen concentration, tree species and biomass, and abundances of saprotrophic Agaricomycetes and ectomycorrhizal fungi (Table 1). However, the correlation was only marginally significant, and inclusion of Cortinarius presence increased the predictive power of the model only moderately, decreasing AIC from -201.5 to -204.0 and increasing $R^{2}$ from 0.23 to 0.25 . However, presence of a single group of closely related species in the genus - Cortinarius acutus s.l. - correlated more strongly ( $p=0.0015)$ and negatively with the amount of organic matter in the topsoil (Table 1). Inclusion of this narrow group of species improved the capacity of a statistical model to predict carbon stocks more clearly, decreasing AIC to -210.2 and increasing $\mathrm{R}^{2}$ to 0.28 (Fig. S6). Carbon stocks in the organic layer were $33 \%$ smaller in the presence of C. actutus s.l. (Figure 1, Fig. S5), with the standardised effect size on carbon stocks being in the same range as effects of temperature, soil nitrogen and saprotroph abundance (Figure 2, Table S1). None of the other groups of the core Agaricomycetes community correlated significantly with carbon stocks $(p>0.1)$. Relaxation of phylogenetic resolution, using a lower sequence similarity threshold to cluster a wider range of Cortinarius species, led to loss of statistical power, as did separation of the $C$. acutus s.l. complex into several taxa by application of a higher sequence similarity threshold (Fig. S2).

Organic matter stocks also decreased significantly with increasing relative abundance of saprotrophic Agaricomycetes in the fungal communities (Figure 2, Table S1) but did not correlate significantly with the over-all relative abundance of ectomycorrhizal fungi. Organic matter stocks correlated positively with warmer temperatures and a higher contribution of spruce 


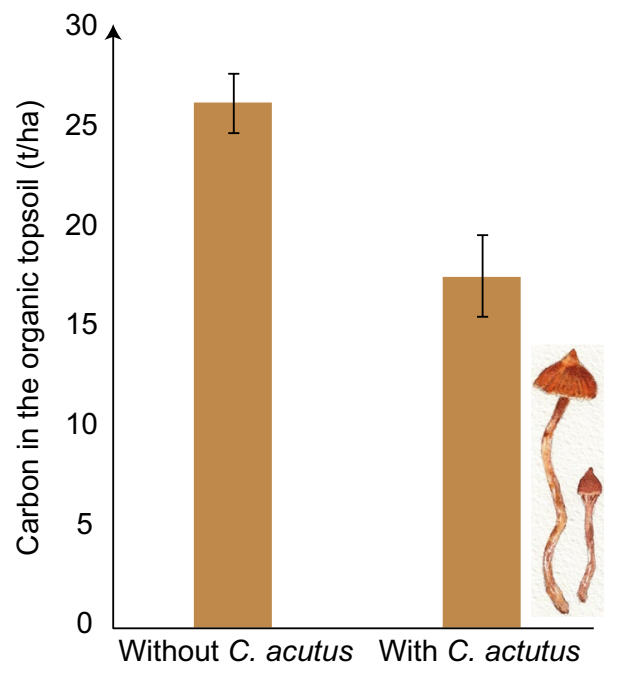

F I G URE 1 Carbon stocks in the organic topsoil of old Swedish boreal forest stands with, or without, presence of the ectomycorrhizal fungus Cortinarius acutus s.l., which was recorded as present when the species accounted for $>1 \%$ of fungal ITS2 sequences $(N=23)$, otherwise as absent $(N=150)$. Bars represent averages \pm SE. Artwork: Liza Johansson

among tree species, but negatively with the nitrogen concentration in organic matter. Soil $\mathrm{pH}$ and nitrogen, spruce abundance and tree biomass were all positively related with each other, together indicating high ecosystem fertility (Fig. S3). The over-all contribution of Agaricomycetes to the total fungal community tied in with these fertility indicators, as saprotroph abundance correlated positively with $\mathrm{pH}$ and soil nitrogen, whereas ectomycorrhizal fungi correlated positively with tree biomass. In contrast, C. acutus s.l. occurred most frequently in forests with low nitrogen concentration in the soil (Figure 3). DNA of C. acutus s.l. was encountered in $13 \%$ of the stands, evenly distributed across the study area, indicating that mycelium of this species occurs ubiquitously in Swedish boreal forests.

When the sample set was expanded to 359 stands by including young forests planted after clear-cutting, C. acutus s.l. was not detected in stands younger than 29 years, and its incidence increased progressively with stand age (Figure 4). This correlation remained significant when the over-all abundance of ectomycorrhizal taxa in the fungal community was included as a covariate (Figure 5, Table S2). Soil nitrogen concentration correlated negatively with both stand age and C. acutus s.l., and a major part of the positive influence of stand age on C. acutus s.l. was estimated as indirect via decreasing nitrogen levels in older stands. However, the direct correlation between stand age and presence of $C$. acutus s.l. remained marginally significant.

\section{DISCUSSION}

The results confirmed our a priori hypothesis that presence of Cortinarius species would coincide with low

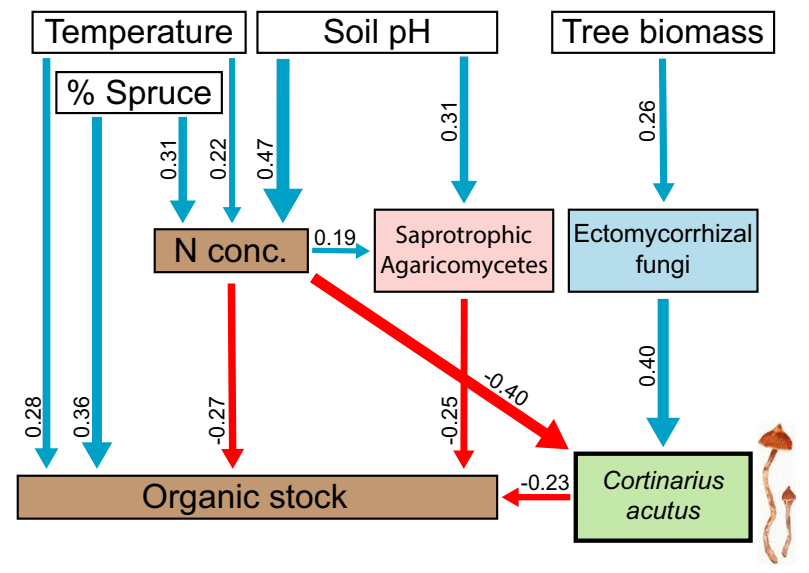

F IGURE 2 Correlations between properties of stands, soils and fungal communities across old stands of Swedish boreal forest $(N=173)$ with organic stocks in the topsoil as the ultimate dependent variable. Numbers represent standardised correlation coefficients, established in a structural equation model, and are reflected by arrow width with blue arrows indicating positive correlations and red arrows indicating negative correlations. "N conc." refers to the square-root transformed nitrogen concentration of organic matter (N:C). "Temperature" refers to the annual temperature sum. "Soil $\mathrm{pH}$ " refers to the log transformed $\mathrm{pH}$ in the organic topsoil. "Tree biomass" refers to basal area. "\% Spruce" refers to the proportion of Picea abies among conifer basal area (the rest being Pinus sylvestris), "Ectomycorrhizal fungi" and "Saprotrophic Agaricomycetes" refers to the relative sequence abundances of ectomycorrhizal fungi (square root transformed) and saprotrophic Agaricomycetes (log transformed) among fungal ITS2 sequences. "Cortinarius acutus" refers to presence of C. acutus s.1. (>1\% of fungal ITS2 sequences required to be recorded as present). "Organic stock" refers to the log transformed amount of carbon in the organic topsoil expressed on an area basis. Artwork: Liza Johansson

organic matter accumulation, which was based on previous literature (Bödeker et al., 2014; Clemmensen et al., 2021; Clemmensen et al., 2015; Kyaschenko et al., 2017b; Pérez-Izquierdo et al., 2021; Sterkenburg et al., 2018). However, whereas presence of the Cortinarius genus as a whole was only moderately important in predicting carbon stocks, correlation was much improved by restricting the selection to a narrow sub-group of the genus - the $C$. acutus s.l. species complex. Our finding that presence of a single fungal species complex was significantly related to organic matter accumulation at the ecosystem scale is consistent with a low degree of microbial redundancy, even for the supposedly "broad" process of decomposition. Thus, our results do not support previous claims of a high degree of functional redundancy among communities of forest soil fungi in biogeochemical processes (Talbot et al., 2014) and challenge the idea that relevant functional guilds of microorganisms would only be defined at high phylogenetic levels (Schimel \& Schaeffer, 2012).

An active role of C. acutus s.l. as a "mycorrhizal decomposer" seems plausible, given the occurrence and expression of manganese peroxidase genes in the genus (Bödeker et al., 2014) combined with the central role of 


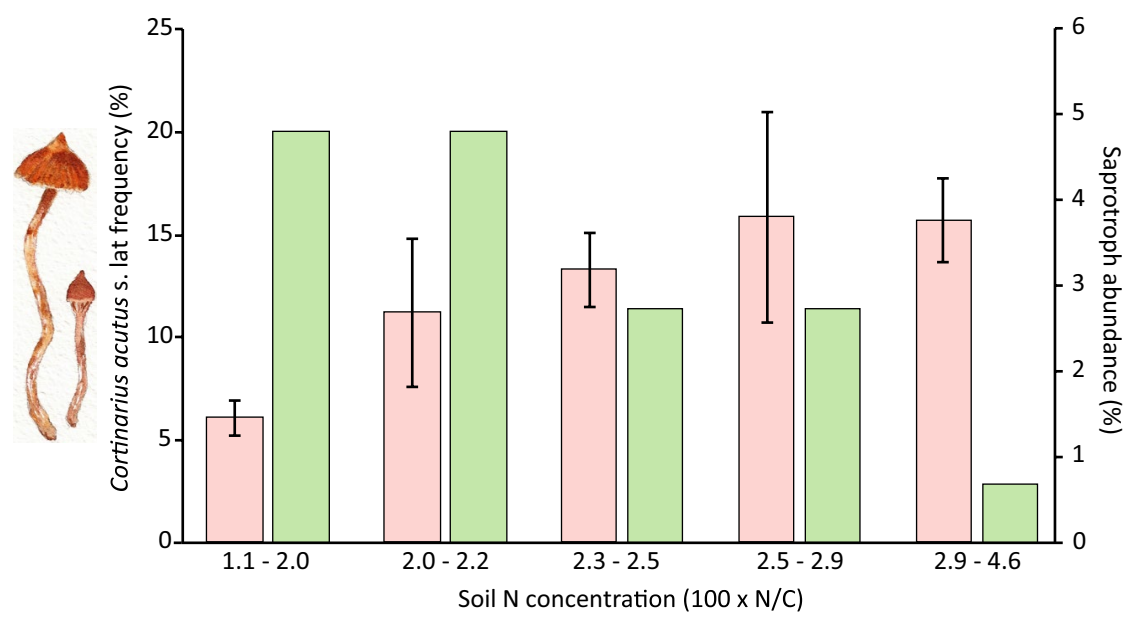

F IG U R E 3 Abundance of saprotrophic Agaricomycetes and frequency of occurrence of the ectomycorrhizal fungus Cortinarius acutus s.1. in organic topsoils of old stands of Swedish boreal forests. Fungal abundances are related to soil nitrogen concentration with data separated in quintiles according to the nitrogen concentration in the topsoil $(N=34-35)$. Relative abundances of saprotrophic Agaricomycetes (red bars; right y-axes; error bars $=\mathrm{SE}$ ) are based on sequencing of amplified ITS2 markers. Frequency of occurrence of $C$. acutus s.1. among the stands (green bars; left $\mathrm{y}$-axes) is based on presence/absence requiring that the species accounted for $>1 \%$ of the fungal ITS2 sequences to be recorded as present. Artwork: Liza Johansson

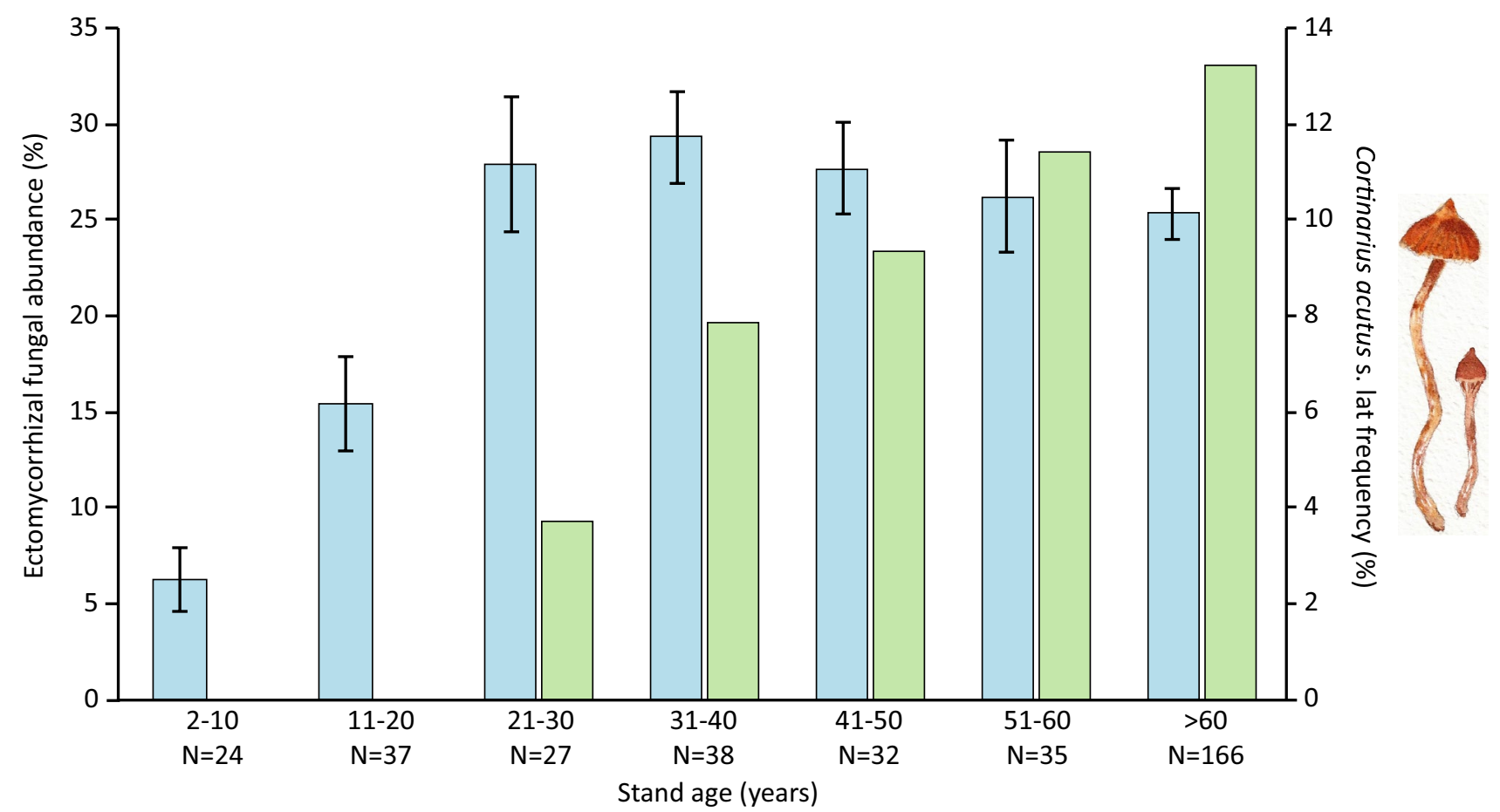

F I G U R E 4 Total abundance of ectomycorrhizal fungi and frequency of occurrence of the ectomycorrhizal fungus Cortinarius acutus s.l. in organic topsoils of Swedish boreal forest in relation to stand age. Data are organised according to age classes ranging from recently clear-cut and planted stands to old forests. Relative abundances of ectomycorrhizal fungi (blue bars; left y-axis; error bars = SE) are based on sequencing of amplified ITS2 markers. Frequency of occurrence of C. acutus s.l. (green bars; right y-axis) among the stands is based on presence/absence requiring that the species accounted for $>1 \%$ of the fungal ITS 2 sequences to be recorded as present. Artwork: Liza Johansson

these enzymes in litter decomposition (Keiluweit et al., 2015) and a strong negative link between organic matter stocks and manganese availability in boreal forests (Stendahl et al., 2017). Our results, thus, support the idea that certain ectomycorrhizal fungi may complement, and even replace, saprotrophs as decomposers when strong nutrient limitation makes it favourable for trees to invest in symbionts to facilitate nutrient mobilisation from recalcitrant organic matter (Baskaran et al., 2017; Lindahl \& Tunlid, 2015). Since nutrient cycling and ecosystem production in boreal forests depend on turnover of the organic topsoil (Kyaschenko 


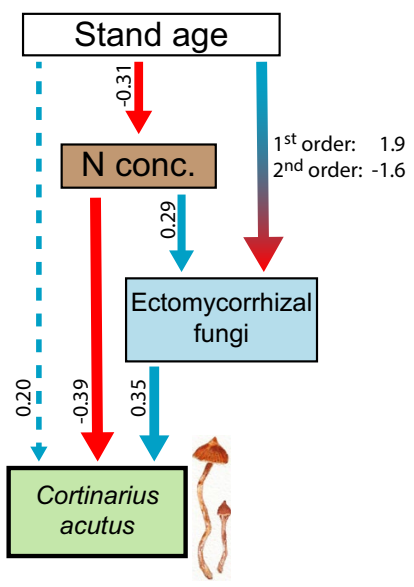

F I G U R E 5 Correlations between stand age, soil nitrogen and ectomycorrhizal fungi across Swedish boreal forest stands, including younger forests planted after clear-cutting $(N=359)$ with occurrence of the ectomycorrhizal fungus Cortinarius acutus s.l. as the ultimate dependent variable. Numbers represent standardised correlation coefficients, established in a structural equation model, and are reflected by arrow width, with blue arrows indicating positive correlations and red arrows indicating negative correlations. The hatched line indicates that the correlation was marginally significant. "Stand age" refers to the average age of trees weighted by basal area and was tested both with and without square-root transformation (to enable second order dependencies). "N conc." refers to the square-root transformed nitrogen concentration of organic matter (N:C). "Ectomycorrhizal fungi" refers to the relative sequence abundances of ectomycorrhizal fungi (square root transformed) among total fungal ITS2 sequences. "Cortinarius acutus" refers to presence of C. acutus s.1. (>1\% of total sequences required to be recorded as present). Artwork: Liza Johansson

et al., 2019), our observations are in line with previous theoretical proposals that ecosystem functionality may depend on a non-redundant interplay between fungal traits and community composition (Crowther et al., 2014; Koide et al., 2014), even on large spatial scales. Yet, in the absence of direct experimental evidence, the causal mechanism behind the correlation remains tentative. We cannot exclude the possibility that thin organic topsoils selectively favour establishment of C. acutus s.l., or that fast decomposition and presence of C. acutus s.l. both depended on a confounding factor that we did not measure.

We also found that organic matter stocks decreased with increasing relative abundance of saprotrophic Agaricomycetes in the fungal communities, which in turn correlated positively with $\mathrm{pH}$ and soil nitrogen, in agreement with previous observations (Sterkenburg et al., 2015). These links support the wider occurrence of a positive feedback between free-living fungal decomposers and soil fertility, as proposed based on local observations (Kyaschenko et al., 2017a). In contrast, C. acutus s.l. occurred most frequently in forests with low nitrogen concentration in the soil (Figure 3), in line with descriptions of Cortinarius as a generally nitrophobic genus (Lilleskov et al., 2019). Thus, while acidity and nutrient limitation seem to constrain efficient (i.e. manganese peroxidase producing) saprotrophic decomposers, symbiotic carbon support may enable $C$. acutus s.l. to persist and maintain decomposition under stressful conditions. This correlative pattern suggests that environmental filtering among non-redundant decomposers, including some mycorrhizal species, plays a major role in regulating belowground organic matter stocks in this system. While both organic matter oxidation and ectomycorrhizal symbiosis may be considered as "broad" traits with high redundancy, the combination of these two traits in a single organism could be considered a more "narrow" feature, to the extent that efficient decomposition may depend on the population dynamics of a handful of species. The negative correlation between $C$. acutus s.l. and soil nitrogen is probably based on bi-directional causalities. C. acutus s.l. is favoured by carbon from nutrient limited tree hosts, but its selective mining for nutrients to sustain tree growth, in turn, reduce soil nitrogen (Clemmensen et al., 2015; Kyaschenko et al., 2019) and intensify nutrient limitation outside the symbiosis. The fungi would thereby mediate a positive plant-soil feedback, which is characteristic of ectomycorrhizal systems (Bennett et al., 2017) and essential to counteract ecosystem retrogression under less fertile conditions (Clemmensen et al., 2013, 2015).

Previous local studies (Averill \& Hawkes, 2016; Gadgil \& Gadgil, 1975; Kyaschenko et al., 2017a), global analyses (Averill et al., 2014) and theoretical models (Orwin et al., 2011) have suggested that ectomycorrhizal fungi generally increase soil carbon storage by competing with saprotrophic decomposers. Here, no positive correlation was observed between the over-all relative abundance of ectomycorrhizal fungi and organic stocks. Rather, within the context of boreal forest, certain ectomycorrhizal species seem to restrict local carbon storage in the soil, plausibly by taking active part in decomposition (Baskaran et al., 2017; Lindahl \& Tunlid, 2015). This difference among ectomycorrhizal fungi highlights the drawbacks of categorising organisms into fixed guilds with uniform functional properties (Zak et al., 2019). However, the negative association of certain ectomycorrhizal species, such as C. acutus s.l., with organic matter accumulation is probably only relevant within the context of the over-all slow decomposition and larger soil organic matter stocks of ectomycorrhizal ecosystems compared to temperate forests dominated by arbuscular mycorrhiza (Phillips et al., 2013; Read \& Perez-Moreno, 2003).

The minuscule spatial scale of microbial habitats promotes high diversity and functional redundancy on larger scales (Nannipieri et al., 2003), and Schimel (1995) envisioned that "the challenge of relating microbial diversity to ecosystem function is fundamentally one of relating the scales of microbial life to the scale of the ecosystem". Agaricomycetes differ from other microorganisms by their mycelia that sometimes extend 
over several square meters, acting as co-ordinated individuals that forage for resources in the heterogeneous soil. The composition of ectomycorrhizal communities is commonly patchy at the meter scale (Pickles et al., 2010), and individual mycelia may occupy the same habitat for decades (Dahlberg \& Stenlid, 1994). Our snapshots of fungal communities suggest that fungal species, most likely individual mycelia, can dominate a $3 \mathrm{~m}^{2}$ habitat for sufficiently long periods to regulate organic matter storage in the topsoil. It may be questioned if these fungi really fit within the general concept of "microorganisms", as they seem to operate at a similar spatiotemporal scale as trees.

Due to insufficient statistical power, we were only able to pinpoint one particularly frequent taxon, but a potential guild of "ectomycorrhizal decomposers" would probably contain many taxa both within and outside the genus Cortinarius. The genus Cortinarius as a whole was marginally significant as a predictor of carbon stocks, and other Cortinarius groups than C. acutus s.l. also tended to correlate negatively with organic matter accumulation (Table 1). Still, the strength of correlation varied within the genus, as previously found for manganese peroxidase activity (Bödeker et al., 2014). The ectomycorrhizal Suillus variegatus also tended to co-localise with low carbon stocks (Table 1), but Suillus species do not possess manganese peroxidases (Kohler et al., 2015) and rather use Fenton chemistry to oxidise organic matter (Shah et al., 2016). "Mat forming" mycorrhizal Hysterangium species have also been connected to high rates of decomposition in North American Douglas fir forests (Entry et al., 1991).

Allison and Martiny (2008) stated that "only if community composition is sensitive to a disturbance, not resilient, and functionally dissimilar to the original community do changes in community composition matter for predicting ecosystem process rates". We assessed the sensitivity and resilience of C. acutus s.1. to stand-replacing disturbance and did not detect the species group in clear-cut and replanted forests younger than 29 years. The decreasing incidence of C. acutus s.l. in younger stands diverged from the over-all abundance of ectomycorrhizal fungi, which recovered faster after clear-cutting (Figure 4; Figure 5, Table S3). Thus, these fungi are less resilient to host deprivation than other ectomycorrhizal taxa, similar to many other Cortinarius species (Kyaschenko et al., 2017b; Varenius et al., 2017). High nutrient availability after disturbance seems to act as an environmental filter that suppresses reestablishment of the nitrophobic C. acutus s.1.. Yet, other mechanisms, such as constraints on dispersal and priority effects of more rapid mycorrhizal colonisers, may also contribute to the delayed re-establishment after clear-cutting. Our finding that a group of fungal species with a central role in organic matter turnover and nutrient cycling is sensitive to disturbance and have low resilience is important in the context of climate change, as increasing incidence of e.g. wildfire and insect pest outbreaks may have negative effects on mycorrhizal functions (Štursová et al., 2014; Rodriguez-Ramos et al. 2021; Perez-Izquierdo et al. 2021). Furthermore, our results raise concerns about the long-term sustainability of stand-replacing forestry operations (Kyaschenko et al., 2017a; Varenius et al., 2017). On a local scale, delayed recolonisation by mycorrhizal decomposers after natural disturbances or forestry operations may increase carbon sequestration in the organic topsoil, but at the same time impede long-term nutrient cycling and forest productivity. On larger scales, declining populations of mycorrhizal keystone species may put central ecosystem functions at risk, with nitrogen poor forests expected to be particularly sensitive.

\section{ACKNOWLEDGEMENTS}

Authors thank the Swedish National Forest and Forest Soil Inventories for sampling and collection of field data. The Swedish Forest Soil Inventory is part of the national environmental monitoring commissioned by the Swedish Environmental Protection Agency. Further, we acknowledge Dr. Rena Gadjieva and the SLU Metabarcoding Laboratory UMBLA for molecular laboratory work, SciLifeLab NGI Uppsala for PacBio sequencing, the SLU Soil and Plant laboratory for chemical analyses, Dr. Jonathan Lefcheck for assistance with statistical modelling and Liza Johansson for illustrations. The project was funded by grants from the Swedish Research Council FORMAS (grant 2011-1747 to B.D.L. and 20121257 to A.D.), the Skogssällskapet, Konsul Faxe, Carl Trygger and Anna and Gunnar Vidfeldt foundations (all to A.D) and by support from the Swedish Environmental Protection Agency.

\section{AUTHOR CONTRIBUTIONS}

B.D.L. initiated and led the project, assembled and analysed the data and wrote the manuscript with input from all co-authors. J.K. and K.V. contributed to the acquisition of fungal community data and initiated the statistical modelling. K.E.C. contributed expertise on fungal ecology, bioinformatics and statistics. A.D. initiated the project and contributed expertise of fungal ecology and taxonomy. E.K. contributed expertise on physical geography and biogeochemistry. J.S. initiated the project, led the sampling campaign, assembled stand and soil data and contributed expertise on physical geography and biogeochemistry.

\section{PEER REVIEW}

The peer review history for this article is available at https://publons.com/publon/10.1111/ele.13746.

\section{DATA AVAILABILITY STATEMENT}

All data are available at Dryad (http://dx.doi.org/10.5061/ dryad.g4f4qrfpp), except sequence data, which are available at NCBI SRA as Bioproject PRJNA693127. 


\section{OPEN RESEARCH BADGES}

\section{III}

This article has earned Open Data badge. Data is available at http://dx.doi.org/10.5061/dryad.g4f4qrfpp; https:// www.ncbi.nlm.nih.gov/bioproject/?term=prjna693127.

\section{ORCID}

Björn D. Lindahl (1D https://orcid.org/0000-0002-3384-4547 Julia Kyaschenko (1) https://orcid.org/0000-0001-8831-8483

Karina E. Clemmensen (D) https://orcid. org/0000-0002-9627-6428

Anders Dahlberg (10 https://orcid.org/0000-0002-3669-6797

Erik Karltun (i) https://orcid.org/0000-0002-1317-1146

Johan Stendahl $\mathbb{D}$ https://orcid.org/0000-0002-9944-0297

\section{REFERENCES}

Adamczyk, B., Sietiö, O.M., Straková, P., Prommer, J., Wild, B., Hagner, M. et al. (2019) Plant roots increase both decomposition and stable organic matter formation in boreal forest soil. Nature Communications, 10, 3982.

Allison, S.D. \& Martiny, J.B.H. (2008) Resistance, resilience, and redundancy in microbial communities. Proceedings of the National Academy of Sciences of the United States of America, 105, 11512-11519.

Andrén, O. \& Balandreau, J. (1999) Biodiversity and soil functioningfrom black box to can of worms? Applied Soil Ecology, 13, 105-108.

Averill, C. \& Hawkes, C.V. (2016) Ectomycorrhizal fungi slow soil carbon cycling. Ecology Letters, 19, 937-947.

Averill, C., Turner, B.L. \& Finzi, A.C. (2014) Mycorrhiza-mediated competition between plants and decomposers drives soil carbon storage. Nature, 505, 543-545.

Banerjee, S., Schlaeppi, K. \& van der Heijden, M.G.A. (2018) Keystone taxa as drivers of microbiome structure and functioning. Nature Reviews Microbiology, 16, 567-576.

Baskaran, P., Hyvönen, R., Berglund, S.L., Clemmensen, K.E., Ågren, G.I., Lindahl, B.D. et al. (2017) Modelling the influence of ectomycorrhizal decomposition on plant nutrition and soil carbon sequestration in boreal forest ecosystems. New Phytologist, 213, 1452-1465.

Bennett, J.A., Maherali, H., Reinhart, K.O., Lekberg, Y., Hart, M. \& Klironomos, J. (2017) Plant-soil feedbacks and mycorrhizal type influence temperate forest population dynamics. Science, 355, 181-184.

Bödeker, I.T.M., Clemmensen, K.E., de Boer, W., Martin, F., Olson, Å. \& Lindahl, B.D. (2014) Ectomycorrhizal Cortinarius species participate in enzymatic oxidation of humus in northern forest ecosystems. New Phytologist, 203, 245-256.

Castaño, C., Berlin, A., Brandström Durling, M., Ihrmark, K., Lindahl, B.D., Stenlid, J. et al. (2020) Optimized metabarcoding with Pacific Biosciences enables semi-quantitative analysis of fungal communities. New Phytologist, 228, 1149-1158.

Clemmensen, K.E., Bahr, A., Ovaskainen, O., Dahlberg, A., Ekblad, A., Wallander, H. et al. (2013) Roots and associated fungi drive long-term carbon sequestration in boreal forest. Science, 339, $1615-1618$

Clemmensen K.E., Brandström Durling M., Michelsen A., Hallin S., Finlay R. \& Lindahl B.D. (2021) A tipping-point in carbon storage when forest expands into tundra is related to mycorrhizal recycling of nitrogen. Ecology Letters, accepted manuscript. https://doi.org/10.1111/ele.13735

Clemmensen, K.E., Finlay, R.D., Dahlberg, A., Stenlid, J., Wardle, D.A. \& Lindahl, B.D. (2015) Carbon sequestration is related to mycorrhizal fungal community shifts during long-term succession in boreal forests. New Phytologist, 205, 1525-1536.

Clemmensen, K.E., Ihrmark, K., Brandström Durling, M. \& Lindahl, B.D. (2016) Sample preparation for fungal community analysis by high-throughput sequencing of barcode amplicons. In: Martin, F. \& Uroz, S. (Eds.) Microbial environmental genomics. Berlin: Springer, pp. 55-88.

Crowther, T.W., Maynard, D.S., Crowther, T.R., Peccia, J., Smith, J.R. $\&$ Bradford, M.A. (2014) Untangling the fungal niche: the traitbased approach. Frontiers in Microbiology, 5, 579.

Dahlberg, A. \& Stenlid, J. (1994) Size, distribution and biomass of genets in populations of Suillus bovinus (L.: Fr.) Roussel revealed by somatic incompatibility. New Phytologist, 128, 225-234.

DeLuca, T.H. \& Boisvenue, C. (2012) Boreal forest soil carbon: distribution, function and modelling. Forestry, 85, 161-184.

Edgar, R.C. (2010) Search and clustering orders of magnitude faster than BLAST. Bioinformatics, 26, 2460-2461.

Entry, J.A., Donnelly, P.K. \& Cromack, K. (1991) Influence of ectomycorrhizal mat soils on lignin and cellulose degradation. Biology and Fertility of Soils, 11, 75-78.

Fernandez, C.W. \& Kennedy, P.G. (2016) Revisiting the 'Gadgil effect': do interguild fungal interactions control carbon cycling in forest soils? New Phytologist, 209, 1382-1394.

Fernandez, C.W., See, C.R. \& Kennedy, P.G. (2020) Decelerated carbon cycling by ectomycorrhizal fungi is controlled by substrate quality and community composition. New Phytologist, 226, 569-582.

Floudas, D., Binder, M., Riley, R., Barry, K., Blanchette, R.A., Henrissat, B. et al. (2012) The Paleozoic origin of enzymatic lignin decomposition reconstructed from 31 fungal genomes. Science, 336, 1715-1719.

Frey, S.D. (2019) Mycorrhizal fungi as mediators of soil organic matter dynamics. Annual Review of Ecology, Evolution, and Systematics, 50(1), 237-259.

Fridman, J., Holm, S., Nilsson, M., Nilsson, P., Hedström Ringvall, A. \& Ståhl, G. (2014) Adapting National Forest Inventories to changing requirements - the case of the Swedish National Forest Inventory at the turn of the 20th century. Silva Fennica, 48, 1095.

Gadgil, R.L. \& Gadgil, P.D. (1975) Suppression of litter decomposition by mycorrhizal roots of Pinus radiata. N. Z. J. For. Sci., 5, 33-41.

Glassman, S.I., Weihe, C., Li, J., Albright, M.B.N., Looby, C.I., Martiny, A.C. et al. (2018) Decomposition responses to climate depend on microbial community composition. Proceedings of the National Academy of Sciences of the United States of America, 115, 11994-11999.

Graham, E.B., Knelman, J.E., Schindlbacher, A., Siciliano, S., Breulmann, M., Yannarell, A. et al. (2016) Microbes as engines of ecosystem function: When does community structure enhance predictions of ecosystem processes? Frontiers in Microbiology, 7, 214.

Högberg, M.N. \& Högberg, P. (2002) Extramatrical ectomycorrhizal mycelium contributes one-third of microbial biomass and produces, together with associated roots, half the dissolved organic carbon in a forest soil. New Phytologist, 154, 791-795.

Ihrmark, K., Bödeker, I.T.M., Cruz-Martinez, K., Friberg, H., Kubartova, A., Schenck, J. et al. (2012) New primers to amplify the fungal ITS2 region - evaluation by 454 -sequencing of artificial and natural communities. FEMS Microbiology Ecology, 82, 666-677.

Keiluweit, M., Nico, P., Harmon, M.E., Mao, J., Pett-Ridge, J. \& Kleber, M. (2015) Long-term litter decomposition controlled by manganese redox cycling. Proceedings of the National Academy of Sciences of the United States of America, 112, E5253-E5260.

Kohler, A., Kuo, A., Nagy, L.G., Morin, E., Barry, K.W., Buscot, F. et al. (2015) Convergent losses of decay mechanisms and rapid turnover of symbiosis genes in mycorrhizal mutualists. Nature Genetics, 47, 410-415.

Koide, R.T., Fernandez, C. \& Malcolm, G. (2014) Determining place and process: functional traits of ectomycorrhizal fungi that affect both community structure and ecosystem function. New Phytologist, 201, 433-439.

Kõljalg, U., Nilsson, R.H., Abarenkov, K., Tedersoo, L., Taylor, A.F.S., Bahram, M. et al. (2013) Towards a unified paradigm for sequencebased identification of fungi. Molecular Ecology, 22, 5271-5277. 
Kyaschenko, J., Clemmensen, K.E., Hagenbo, A., Karltun, E. \& Lindahl, B.D. (2017b) Shift in fungal communities and associated enzyme activities along an age gradient of managed Pinus sylvestris stands. ISME Journal, 11, 863-874.

Kyaschenko, J., Clemmensen, K.E., Karltun, E. \& Lindahl, B.D. (2017a) Below-ground organic matter accumulation along a boreal forest fertility gradient relates to guild interaction within fungal communities. Ecology Letters, 20, 1546-1555.

Kyaschenko, J., Ovaskainen, O., Ekblad, A., Hagenbo, A., Karltun, E., Clemmensen, K.E. et al. (2019) Soil fertility in boreal forest relates to root-driven nitrogen retention and carbon sequestration in the mor layer. New Phytologist, 221, 1492-1502.

Lefcheck, J.S. (2016) PIECEWISESEM: Piecewise structural equation modelling in $\mathrm{R}$ for ecology, evolution, and systematics. Methods in Ecology and Evolution, 7, 573-579.

Lilleskov, E.A., Kuyper, T.W., Bidartondo, M.I. \& Hobbie, E.A. (2019) Atmospheric nitrogen deposition impacts on the structure and function of forest mycorrhizal communities: a review. Environmental Pollution, 246, 148-162.

Lindahl, B.D. \& Tunlid, A. (2015) Ectomycorrhizal fungi - potential organic matter decomposers, yet not saprotrophs. New Phytologist, 205, 1443-1447.

Mace, G.M., Norris, K. \& Fitter, A.H. (2012) Biodiversity and ecosystem services: a multilayered relationship. Trends in Ecology \& Evolution, 27, 19-26.

McGuire, K.L. \& Treseder, K.K. (2010) Microbial communities and their relevance for ecosystem models: Decomposition as a case study. Soil Biology \& Biochemistry, 42, 529-535.

Nannipieri, P., Ascher, J., Ceccherini, M.T., Landi, L., Pietramellara, G. \& Renella, G. (2003) Microbial diversity and soil functions. European Journal of Soil Science, 54, 655-670.

Nilsson, R.H., Anslan, S., Bahram, M., Wurzbacher, C., Baldrian, P. \& Tedersoo, L. (2019) Mycobiome diversity: high-throughput sequencing and identification of fungi. Nature Reviews Microbiology, 17, 95-109.

Odin, H., Eriksson, B. \& Pertuu, K. (1983) Temperature climate maps for Swedish forestry. 57, Uppsala: Swedish University of Agricultural Sciences.

Orwin, K.H., Kirschbaum, M.U.F., St John, M.G. \& Dickie, I.A. (2011) Organic nutrient uptake by mycorrhizal fungi enhances ecosystem carbon storage: a model-based assessment. Ecology Letters, 14, 493-502.

Pérez-Izquierdo, L., Clemmensen, K.E., Strengbom, J., Granath, G., Wardle, D.A., Nilsson, M.C. et al. (2021) Crown-fire severity is more important than ground-fire severity in determining soil fungal community development in the boreal forest. Journal of Ecology, 109, 504-518.

Philippot, L., Spor, A., Hénault, C., Bru, D., Bizouard, F., Jones, C.M. et al. (2013) Loss in microbial diversity affects nitrogen cycling in soil. ISME Journal, 7, 1609-1619.

Phillips, R.P., Brzostek, E. \& Midgley, M.G. (2013) The mycorrhizalassociated nutrient economy: a new framework for predicting carbon-nutrient couplings in temperate forests. New Phytologist, $199,41-51$

Pickles, B.J., Genney, D.R., Potts, J.M., Lennon, J.J., Anderson, I.C. \& Alexander, I.J. (2010) Spatial and temporal ecology of Scots pine ectomycorrhizas. New Phytologist, 186, 755-768.

Prosser, J.I. (2020) Putting science back into microbial ecology: a question of approach. Philosophical Transactions of the Royal Society B, 375, 20190240.

Read, D.J. \& Perez-Moreno, J. (2003) Mycorrhizas and nutrient cycling in ecosystems - a journey towards relevance? New Phytologist, 157, 475-492.

Rodriguez-Ramos, J.C., Cale, J.A., Cahill, J.F., Simard, S.W., Karst, J. \& Erbilgin, N. (2021) Changes in soil fungal community composition depend on functional group and forest disturbance type. New Phytologist 229, 1105-1117.

Schimel, J.P. (1995) Ecosystem consequences of microbial diversity and community structure. In: Chapin, F.S. \& Körner, C. (Eds.)
Arctic and alpine biodiversity: Patterns, causes and ecosystem consequences. Ecological studies (Analysis and Synthesis). 113, Berlin: Springer, pp. 239-254.

Schimel, J.P. \& Schaeffer, S.M. (2012) Microbial control over carbon cycling in soil. Frontiers in Microbiology, 3, 348 .

Schloter, M., Nannipieri, P., Sørensen, S.J. \& van Elsas, J.D. (2018) Microbial indicators for soil quality. Biology and Fertility of Soils, 54, 1-10

Schmidt, M.W.I., Torn, M.S., Abiven, S., Dittmar, T., Guggenberger, G., Janssens, I.A. et al. (2011) Persistence of soil organic matter as an ecosystem property. Nature, 478, 49-56.

Shah, F., César, N., Bentzer, J., Ellström, M., Smits, M., Rineau, F. et al. (2016) Ectomycorrhizal fungi decompose humus-rich litter material using oxidative mechanisms retained from saprotrophic ancestors. New Phytologist, 209, 1705-1719.

Smith, G.R. \& Wan, J. (2019) Resource-ratio theory predicts mycorrhizal control of litter decomposition. New Phytologist, 223, $1595-1606$

Stendahl, J., Berg, B. \& Lindahl, B.D. (2017) Manganese availability is negatively associated with carbon storage in northern coniferous forest humus layers. Scientific Reports, 7, 15487.

Sterkenburg, E., Bahr, A., Brandström Durling, M., Clemmensen, K.E. \& Lindahl, B.D. (2015) Changes in fungal communities along a boreal forest soil fertility gradient. New Phytologist, 207, $1145-1158$.

Sterkenburg, E., Clemmensen, K.E., Ekblad, A., Finlay, R.D. \& Lindahl, B.D. (2018) Contrasting effects of ectomycorrhizal fungi on early and late stage decomposition in a boreal forest. ISME Journal, 12, 2187-2197.

Strickland, M.S., Lauber, C., Fierer, N. \& Bradford, M.A. (2009) Testing the functional significance of microbial community composition. Ecology, 90, 441-451.

Štursová, M., Šnajdr, J., Cajthaml, T., Bárta, J., Šantrůčková, H. \& Baldrian, P. (2014) When the forest dies: the response of forest soil fungi to a bark beetle-induced tree dieback. ISME Journal, 8, 1920-1931.

Talbot, J.M., Bruns, T.D., Smith, D.P., Branco, S., Glassman, S.I., Erlandson, S. et al. (2013) Independent roles of ectomycorrhizal and saprotrophic communities in soil organic matter decomposition. Soil Biology \& Biochemistry, 57, 282-291.

Talbot, J.M., Bruns, T.D., Taylor, J.W., Smith, D.P., Branco, S., Glassman, S.I. et al. (2014) Endemism and functional convergence across the North American soil mycobiome. Proceedings of the National Academy of Sciences of the United States of America, 111, 6341-6346.

Varenius, K., Lindahl, B.D. \& Dahlberg, A. (2017) Retention of seed trees fails to lifeboat ectomycorrhizal fungal diversity in harvested Scots pine forests. FEMS Microbiology Ecology, 93, fix105.

Wang, Y., Naumann, U., Wright, S.T. \& Warton, D.I. (2012) mvabund - an R package for model-based analysis of multivariate abundance data. Methods in Ecology and Evolution, 3, 471-474.

Zak, D.R., Pellitier, P.T., Argiroff, W.A., Castillo, B., James, T.Y., Nave, L.E. et al. (2019) Exploring the role of ectomycorrhizal fungi in soil organic matter dynamics. New Phytologist, 223, 33-39.

\section{SUPPORTING INFORMATION}

Additional supporting information may be found online in the Supporting Information section.

How to cite this article: Lindahl BD, Kyaschenko J, Varenius K, et al. A group of ectomycorrhizal fungi restricts organic matter accumulation in boreal forest. Ecology Letters. 2021;24:1341-1351. https:// doi.org/10.1111/ele. 13746 